\title{
ESTÁGIO SUPERVISIONADO: PROJETOS CRIATIVOS ECOFORMADORES NA FORMAÇÃO INICIAL DE PROFESSORES DE QUÍMICA
}

\author{
Mariana Schneider \\ Instituto Federal de Santa Catarina - IFSC Campus São José (Brasil) \\ schneider.mari@hotmail.com · https://orcid.org/0000-0002-9670-4322 \\ Paula Alves de Aguiar \\ Instituto Federal de Santa Catarina - IFSC Campus São José (Brasil) \\ paula.aguiar@ifsc.edu.br·https://orcid.org/0000-0003-0776-9472 \\ Franciele Drews de Souza \\ Instituto Federal de Santa Catarina - IFSC Campus São José (Brasil) \\ francieledrews@gmail.com · https://orcid.org/0000-0001-5144-8970
}

\begin{abstract}
Resumo. Este texto tem como objetivo analisar o desenvolvimento dos Componentes Curriculares de Estágio Supervisionado do Curso de Licenciatura em Química do Instituto Federal de Santa Catarina, Campus São José (IFSC-SJ). Buscou-se perceber de que forma os Projetos Criativos Ecoformadores (PCEs), elaborados e aplicados durante os Estágios Supervisionados II e III, podem contribuir para a formação de professores pesquisadores, como preveem os referenciais teóricos de estágio adotados no referido curso. Como aportes teórico-conceituais foram utilizados, para a formação de professores, Pimenta (1999), Pimenta e Lima (2005/2006), Lüdke (2012) e, para discutir a respeito dos componentes curriculares de Estágio Supervisionado no curso de Licenciatura em Química, foram utilizados conceitos do PPC do referido curso (IFSC, 2014). Os PCEs analisados foram elaborados, como projetos de intervenção, pelos licenciandos da primeira turma que cursou o Estágio Supervisionado II do referido curso, em 2018/1, e desenvolvidos em Estágio Supervisionado III, em 2018/2. Para realizar a presente análise, foram investigados oito projetos, visando perceber suas características gerais, como utilizaram a proposta metodológica dos PCEs e sua relação com os objetivos do estágio na formação de professores pesquisadores. A partir dos resultados obtidos, foi possível levantar indícios a respeito de como estão sendo formados os professores no curso analisado e quais os reflexos dessa proposta no planejamento das aulas no Estágio Supervisionado.
\end{abstract}

Palavras-chave: Estágio Supervisionado, Projetos Criativos Ecoformadores, Formação Inicial de Professores

\section{SUPERVISED INTERNSHIP: ECOFORMING CREATIVE PROJECTS IN THE INITIAL TRAINING OF TEACHERS OF CHEMISTRY}

\begin{abstract}
In this text the development of the Curricular Components of Supervised Internship of the Chemistry Degree course of the Instituto Federal de Santa Catarina, Campus São José (IFSC-SJ) is analyzed. It is intended to understand the contribution of the Ecoforming Creative Projects (ECPs), elaborated and applied during Supervised Internships II and III, for the training of teachers / researchers, according to the premises of the theoretical frameworks adopted during the course. Pimenta (1999), Pimenta and Lima (2005/2006), Lüdke (2012) provided the theoretical-conceptual input, while the discussions about the curricular components of the Supervised Internship in Chemistry were based on the CPP concepts of that course (IFSC, 2014). The analyzed ECPs were designed, as intervention projects, by the first group of undergraduate students who attended the Supervised Internship II of the mentioned
\end{abstract}


course in 2018/1 and developed in the Supervised Internship III in 2018/2. Eight projects were investigated for the present analysis in order to realize their respective general characteristics and to understand how the methodological proposal of the ECPs was used, as well as their relation with the objectives of the internship in the training of teachers / researchers. Based on the results obtained, there were indications of how teachers are being trained in the analyzed course, besides the implications of this proposal in the planning of Supervised Internship classes.

Keywords: Supervised Internship, Ecoforming Creative Projects, Initial Teacher Training

\title{
PASANTÍA SUPERVISADA: PROYECTOS CREATIVOS ECOFORMADORES EN LA FORMACIÓN INICIAL DE PROFESORES DE QUÍMICA
}

\begin{abstract}
Resumen. En este texto se analiza el desarrollo de los componentes curriculares de la pasantía supervisada de la Licenciatura en Química del Instituto Federal de Santa Catarina, Campus São José (IFSC-SJ). Su objetivo es comprender la contribución de los Proyectos Creativos Ecoformadores (PCEs), elaborados y aplicados durante las Pasantías Supervisadas II y III, para la formación de profesores / investigadores, de acuerdo con las premisas de los marcos teóricos adoptados durante el curso. Pimenta (1999), Pimenta y Lima (2005/2006), Lüdke (2012) proporcionaron el aporte teórico-conceptual, mientras que las discusiones sobre los componentes curriculares de la pasantía supervisada en química se basaron en los conceptos de PPC de ese curso (IFSC, 2014). Los PCEs analizados fueron diseñados, como proyectos de intervención, por el primer grupo de estudiantes de pregrado que asistieron a la Pasantía Supervisada II del curso mencionado en 2018/1 y se desarrollaron en la Pasantía Supervisada III en 2018/2. Se investigaron ocho proyectos para el presente análisis con el fin de percatar sus respectivas características generales y entender cómo se utilizó la propuesta metodológica de lós PCEs, así como su relación con los objetivos de la pasantía en la formación de docentes/investigadores. Sobre la base de los resultados obtenidos, hubo indicaciones de cómo se está capacitando a los profesores en el curso analizado, además de las implicaciones de esta propuesta en la planificación de las clases de pasantías supervisadas.
\end{abstract}

Palabras clave: Pasantía Supervisada, Proyectos Creativos Ecoformadores, Formación Inicial de Profesores.

\section{Introdução}

Este texto pretende descrever os Projetos de Intervenção (PIs) desenvolvidos no ano de 2018, nos estágios do curso de Licenciatura em Química do Instituto Federal de Santa Catarina, campus São José (IFSC-SJ). Buscou-se perceber de que forma eles podem ter contribuído para a formação de professores pesquisadores. A perspectiva teórica de estágio pela pesquisa é prevista nos referenciais adotados no referido curso. Para a análise dos dados aqui apresentados, foram utilizados os PIs elaborados e aplicados pelos licenciandos da primeira turma a cursar os componentes curriculares de Estágio Supervisionado II (ESII) e Estágio Supervisionado III (ESIII), em 2018/1 e 2018/2, respectivamente.

Pesquisas relacionadas à formação de professores, segundo Nunes (2001), apontam para a relevância em analisar as práticas pedagógicas, desenvolvidas por 
docentes e licenciandos, como a análise realizada neste texto. Busca-se, com esse estudo, contribuir para unir a formação e a prática cotidiana das escolas.

A respeito de tal formação, Pimenta (1999, p. 19) aponta que a identidade profissional é construída a partir do "confronto entre as teorias e as práticas, da análise sistemática das práticas à luz das teorias existentes, da construção de novas teorias".

Além disso, os saberes docentes são construídos a partir de reflexões sobre e durante a prática, de forma processual, com a reelaboração de saberes com base nas experiências educativas, que se iniciam ainda no decorrer da formação inicial do professor, com destaque nos Estágios Supervisionados e têm continuidade no decorrer de sua atuação profissional, nos cursos de formação continuada realizados depois de formados, nas instituições em que atuam (Pimenta, 1999). Percebe-se, nesta perspectiva, uma indissociabilidade entre teoria e prática na formação e atuação profissional de professores.

Por mais que a formação do professor seja um processo contínuo, que não termina ao concluir um curso de licenciatura, essa formação inicial possui grande importância no processo de constituição do futuro professor. Ao formar um professor, é importante, no caso da Licenciatura em Química, que o licenciando, além de ter conhecimento de e sobre Química, saiba como ensinar Química e apreenda os saberes da docência (Silva e Oliveira, 2009).

O Estágio Supervisionado (ES) é um momento privilegiado de integração dos saberes químicos com os saberes da docência. Silva e Schnetzler (2008, p. 2175) falam deste como um espaço que favorece a formação teórica com a experiência profissional, bem como que "tal interface teoria-prática compõe-se de uma interação constante entre o saber e o fazer, entre conhecimentos acadêmicos disciplinares e o enfrentamento de problemas decorrentes da vivência de situações próprias do cotidiano escolar".

No curso analisado neste texto, esse momento da licenciatura busca que os professores em formação partam da realidade do contexto educativo, compreendendo suas potencialidades e dificuldades, para propor estratégias de ensino que sejam significativas para os sujeitos envolvidos nas práticas educativas e contribuam para enriquecer a realidade escolar. Nesse sentido, almeja-se que o licenciando, os alunos e os professores das escolas de estágio sejam sujeitos nesse processo de construção de conhecimentos químicos.

Nessa perspectiva, o estágio se torna um momento de experimentar metodologias didático-pedagógicas, de discutir e debater a respeito dos processos de ensino e aprendizagem, com base em leituras e práticas adotadas durante os componentes de ES (Pimenta; Lima, 2004). Parte-se do pressuposto de que a pesquisa na formação de professores oportuniza que os futuros docentes sejam críticos, autônomos e tenham consciência da necessidade de analisar e problematizar sua prática profissional (Lüdke, 2012, Pesce e André, 2012).

A maneira como esses componentes curriculares são organizados e suas principais características serão apresentadas na seção seguinte. 


\section{Os Estágios Supervisionados no curso de Licenciatura do IFSC-SJ}

Inicialmente, para melhor compreensão da proposta que deu origem aos PIs relatados e analisados neste trabalho, é necessário apresentar o que é previsto, para os componentes curriculares de ES, no Projeto Pedagógico do Curso (PPC) de Licenciatura em Química do IFSC-SJ. Os componentes curriculares de ES possuem os seguintes objetivos, de acordo com IFSC (2014):

1) O Estágio Supervisionado I (ESI), tem como objetivo: identificar diferentes campos de atuação e distintos espaços educativos; compreender o processo de pesquisa na formação docente; conhecer procedimentos éticos de pesquisa, e; desenvolver formas de observação que possibilitem refletir sobre a prática pedagógica. No decorrer deste estágio, são produzidos diários de campo (Zabalza, 2004), relacionados às visitas realizadas nos diferentes espaços educativos, como instrumento de registro e reflexão, de modo a caracterizar o processo de pesquisa no estágio.

2) Os objetivos do Estágio Supervisionado II (ESII) são: compreender o processo de pesquisa e reflexão de práticas pedagógicas em espaços formais de ensino de Química; refletir sobre a pesquisa e a intervenção a partir das diferentes perspectivas epistemológicas; realizar observações em espaços educativos formais para a definição de uma temática para o Projeto de Intervenção (PI); elaborar um PI, e; pensar e/ou elaborar um material didático relacionado à temática para ser utilizado no desenvolvimento do PI. No decorrer do estágio é realizada a escolha da modalidade de ensino e do campo de estágio em que serão realizadas as regências, no semestre seguinte. Após a escolha, são realizadas 08 observações participantes (Tura, 2003) de aulas de Química. Então, é feita uma atividade investigativa com os alunos, com o objetivo de definir a temática que será utilizada como base para a construção dos PIs, que também é realizada nessa etapa do estágio.

3) O Estágio Supervisionado III (ESIII) possui como objetivo: estabelecer relações entre teoria e prática, para análise da regência; elaborar instrumentos de pesquisa e didáticos que possibilitem a coleta de dados a respeito do estágio; realizar o tratamento dos dados obtidos durante a regência, e; registrar as regências e os resultados obtidos através do desenvolvimento do PI em um portfólio. Dessa forma, nesse estágio, são realizadas as aulas de regência, aplicando-se o PI elaborado no estágio anterior, e utilizando e/ou desenvolvendo com a turma o material didático.

4) Os objetivos do Estágio Supervisionado IV (ESIV) são: estabelecer relações entre teoria e prática para análise do desenvolvimento do PI; elaborar um relato de experiência utilizando fundamentosteórico/metodológicos a respeito das vivências nos estágios anteriores. Sendo assim, são construídos relatos de experiência com base nas vivências de todos os estágios.

Dessa forma, durante os componentes curriculares de ES no curso de Licenciatura em Química, os licenciandos utilizam diferentes processos de pesquisa e investigação, com a intenção de compreender melhor as práticas educativas vivenciadas nas escolas e, também, para elaborar e desenvolver os PI, possibilitando assim uma reflexão crítica a respeito de processos escolares e do próprio processo de formação docente. 
Sobre as pesquisas nesse processo de formação, Pimenta e Lima (2005/2006, p. 14), afirmam que são possibilidades de ampliação e análise dos contextos educativos, além de serem uma forma de os licenciandos "desenvolverem postura e habilidades de pesquisador... a partir das situações de estágio, elaborando projetos que lhes permitam ao mesmo tempo compreender e problematizar as situações que observam".

Nesse sentido, a respeito da construção e aplicação dos PIs, atividades desenvolvidas no decorrer dos componentes curriculares de ESII e ESIII, em que a pesquisa está presente em todos os momentos, esses projetos são construídos utilizandose como referência a proposta metodológica dos Projetos Criativos Ecoformadores (PCEs) (Torre e Zwierewicz, 2009). Embora a opção por essa metodologia não esteja explícita no PPC do curso, os referenciais teóricos previstos nas ementas dos componentes curriculares contemplam essa proposta, que se reflete na prática dos estágios atualmente desenvolvidos na instituição.

De acordo com Aguiar, Viella e Pereira (2017, p. 132), a metodologia dos PCEs, que é "amparada no paradigma ecossistêmico, no pensamento complexo, na transdisciplinaridade e na ecoformação", busca a autonomia, transformação, colaboração e o desenvolvimento integral dos alunos.

A diferença entre PCEs e outros tipos de projetos, segundo Zwierewicz (2016, p. 401-402), está em desenvolver propostas de "ensino a partir da vida, voltando-se para esta com soluções projetadas no contexto de aplicação, por meio da implicação de situações e recursos que vão além da simples reprodução do conhecimento científico". A proposta busca conhecer as realidades educativas, suas potencialidades e dificuldades para desenvolver projetos que contribuam com a comunidade escolar.

No curso aqui analisado, almeja-se, segundo sua proposta curricular, formar professores que não só ensinem os fundamentos da Química, sua relação histórica e interação com diferentes áreas, mas que busquem o pleno desenvolvimento dos alunos, articulando esses saberes com a formação ética, a construção da autonomia intelectual e do pensamento crítico (IFSC, 2004). Nesse contexto, os PCEs passaram a ser utilizados nos ES, por serem um referencial metodológico que corrobora com o perfil do professor que se quer formar, dando mais subsídios para os PIs elaborados no curso.

Este trabalho tem como objetivo descrever e analisar os PIs desenvolvidos pela primeira turma de ES do curso de Licenciatura em Química do IFSC-SJ, buscando perceber de que forma os mesmos têm contribuído para a formação de professores pesquisadores, como previsto nas competências expostas no PPC do curso (IFSC, 2014).

A abordagem de investigação adotada é do tipo qualitativa, apresentando caráter descritivo e pressupostos da pesquisa documental que, de acordo com Neves (1996, p.3), é "constituída pelo exame de materiais que ainda não receberam um tratamento analítico ou que podem ser reexaminados com vistas a uma interpretação nova ou complementar".

Para análise, foram considerados os PIs elaborados, no primeiro semestre de 2018, pela primeira turma a cursar ESII e ESIII. Ao todo, foram analisados 08 projetos elaborados e desenvolvidos pelos licenciandos de forma individual. 


\section{Projetos de Intervenção nos Estágios Supervisionados do curso de Licenciatura em Química}

Os 08 PIs analisados neste artigo, descritos nesta seção, mantêm os mesmos princípios didáticos dos PCEs, porém com algumas adaptações, para se enquadrarem na proposta dos ES, como, por exemplo, o tempo de execução dos PIs acaba sendo limitado a 16 aulas de regência, e também para adequá-los às propostas curriculares e pedagógicas das escolas onde esses projetos foram desenvolvidos. O fato de o estágio estar vinculado apenas à disciplina de química dificulta a realização de atividades $\mathrm{e}$ propostas interdisciplinares; ainda assim, em projetos como o $\mathrm{PI}_{3}$, buscaram a interdisciplinaridade com parcerias na escola, conforme destacado na sequência didática analisada.

Como comentado anteriormente, antes de iniciar a construção dos PIs, foram realizadas, pelos licenciandos, observações participantes e pesquisas, com a intenção de conhecer um pouco sobre a realidade dos alunos, a escola e definir uma temática para o ensino de Química.

Os PIs foram construídos de acordo com as observações realizadas, levando-se em consideração as opiniões dos alunos e baseando-se na proposta dos Projetos Criativos Ecoformadores. Esses projetos foram organizados de forma a apresentar um Epítome, na primeira etapa das aulas, com o objetivo de "encantar" os alunos para a temática proposta no PI. Na última parte do projeto, então, é apresentada a Polinização, realizada com a intenção de divulgar e socializar os resultados alcançados pelos alunos (Aguiar e outros, 2017). Além disso, foi elaborado, em cada PI, um material didático, como forma de envolver e cativar ainda mais os alunos para o projeto proposto.

Nas seções seguintes, haverá um (breve) relato de como foram utilizados os Materiais Didáticos (MD), do desenvolvimento dos Epítomes e das Polinizações de cada um dos 08 PIs analisados. Considera-se que essas partes do projeto são diferenciais dentro da proposta dos PCEs e consequentemente da proposta de estágio analisada. Essas etapas, assim como os MDs construídos pelos licenciandos, representam possibilidades de um ensino com diferentes estratégias metodológicas e recursos didáticos, fornecendo, portanto, indícios para a reflexão sobre o perfil de professores que estão sendo formados no curso de Licenciatura em Química investigado.

Visto isso, apresentam-se a seguir os oito PIs que são objetos de análise do presente trabalho: ambientais;

$\mathrm{PI}_{1}$ : Absorventes íntimos femininos e preservativos masculinos - Impactos

$\mathrm{PI}_{2}$ : Química do cotidiano: $\mathrm{O}$ uso da cozinha como laboratório com alunos de PROEJA;

$\mathrm{PI}_{3}$ : Vermicompostagem na escola: Construção do conhecimento e sustentabilidade visando à valorização da comunidade escolar;

PI 4 : A Química e as Drogas;

$\mathrm{PI}_{5}$ : Polímeros plásticos aplicados à construção civil;

$\mathrm{PI}_{6}$ : Análise de conservantes em produtos cárneos: Uma alternativa pedagógica criativa ecoformadora para técnicos em química;

PI7: A Química dos Aromas; 
PI8: Auxílio de história em quadrinhos, animes e mangás na contextualização dos conteúdos de Química.

Para melhor compreensão, é apresentado a seguir um quadro com alguns detalhes, como a modalidade de ensino e a turma em que os PIs foram aplicados, assim como a temática abordada, o conteúdo químico trabalho e a atividade investigativa utilizada em cada projeto para conhecer os alunos e verificar o interesse deles pela temática proposta.

Tabela 1

Detalhamento dos PIs

\begin{tabular}{|c|c|c|c|c|c|}
\hline & $\begin{array}{c}{[\mathrm{i}]} \\
\text { Modalidade } \\
\text { de Ensino }\end{array}$ & $\begin{array}{l}\text { [ii] Turma } \\
\text { (ano/fase) }\end{array}$ & $\begin{array}{c}\text { [iii] Atividade } \\
\text { Investigativa }\end{array}$ & $\begin{array}{c}\text { [iv] } \\
\text { Conteúdo } \\
\text { trabalhado }\end{array}$ & $\begin{array}{c}{[\mathrm{v}]} \\
\text { Temática abordada }\end{array}$ \\
\hline $\mathbf{I}_{1}$ & EM* Regular & $3^{\circ}$ ano & $\begin{array}{l}\text { Observação } \\
\text { Participante e } \\
\text { Questionário }\end{array}$ & $\begin{array}{l}\text { Isomeria Plana e } \\
\text { Espacial; Ácidos } \\
\text { Carboxílicos e } \\
\text { Ésteres }\end{array}$ & $\begin{array}{l}\text { Absorventes íntimos } \\
\text { femininos e } \\
\text { preservativos } \\
\text { masculinos }\end{array}$ \\
\hline $\mathbf{I}_{2}$ & $\begin{array}{l}\text { Educação de } \\
\text { Jovens e } \\
\text { Adultos } \\
\end{array}$ & $4^{\mathrm{a}}$ fase & $\begin{array}{l}\text { Observação } \\
\text { Participante e } \\
\text { Questionário }\end{array}$ & $\begin{array}{c}\text { Misturas; } \\
\text { Modelos Atômicos; } \\
\text { Reações Químicas }\end{array}$ & $\begin{array}{l}\text { O uso da cozinha } \\
\text { como laboratório }\end{array}$ \\
\hline $\mathbf{I}_{3}$ & EM Regular & $1^{\circ}$ ano & $\begin{array}{l}\text { Observação } \\
\text { Participante e } \\
\text { Roda de } \\
\text { conversa }\end{array}$ & $\begin{array}{l}\text { Substâncias } \\
\text { Inorgânicas: Ácidos, } \\
\text { Bases, Óxidos e Sais }\end{array}$ & $\begin{array}{l}\text { Vermicompostagem } \\
\text { na escola: Construção } \\
\text { do conhecimento e } \\
\text { sustentabilidade } \\
\text { visando à valorização } \\
\text { da comunidade } \\
\text { escolar. }\end{array}$ \\
\hline $\mathbf{I}_{4}$ & EM Regular & $3^{\circ}$ ano & $\begin{array}{l}\text { Observação } \\
\text { Participante e } \\
\text { Questionário }\end{array}$ & $\begin{array}{l}\text { Isomeria Óptica; } \\
\text { Funções Orgânicas } \\
\text { Alcoóis, Éteres e } \\
\text { Aminas }\end{array}$ & $\begin{array}{c}\text { Drogas e } \\
\text { Medicamentos }\end{array}$ \\
\hline $\mathbf{I}_{5}$ & EM Regular & $3^{\circ}$ ano & $\begin{array}{l}\text { Observação } \\
\text { Participante e } \\
\text { Questionário }\end{array}$ & $\begin{array}{c}\text { Funções Orgânicas } \\
\text { Alcoóis, Ácidos } \\
\text { Carboxílicos e } \\
\text { Aminas; } \\
\text { Forças } \\
\text { Intermoleculares; } \\
\text { Densidade; } \\
\text { Polaridade }\end{array}$ & $\begin{array}{c}\text { Polímeros plásticos } \\
\text { aplicados à } \\
\text { construção civil }\end{array}$ \\
\hline $\mathbf{I}_{6}$ & $\begin{array}{l}\text { EM Técnico } \\
\text { Integrado em } \\
\text { Química }\end{array}$ & $8^{a}$ fase & $\begin{array}{l}\text { Observação } \\
\text { Participante e } \\
\text { Questionário }\end{array}$ & $\begin{array}{c}\text { Cromatografia; } \\
\text { Eletroforese } \\
\text { Capilar; Hifenação } \\
\text { Analítica; } \\
\text { Espectrometria de } \\
\text { Massas; } \\
\text { Espectrofotometria }\end{array}$ & $\begin{array}{l}\text { Uso de conservantes } \\
\text { na fabricação de } \\
\text { produtos cárneos }\end{array}$ \\
\hline $\mathbf{I}_{7}$ & EM Regular & $3^{\circ}$ ano & $\begin{array}{l}\text { Observação } \\
\text { Participante e } \\
\text { Questionário }\end{array}$ & $\begin{array}{c}\text { Funções Orgânicas } \\
\text { Alcoóis, Ésteres e } \\
\text { Cetonas; Isomeria } \\
\text { Óptica }\end{array}$ & $\begin{array}{c}\text { A Química presente } \\
\text { nos Aromas }\end{array}$ \\
\hline $\mathbf{I}_{8}$ & EM Regular & $1^{\circ}$ ano & $\begin{array}{l}\text { Observação } \\
\text { Participante e } \\
\text { Questionário }\end{array}$ & $\begin{array}{l}\text { Atomística; Tabela } \\
\text { Periódica }\end{array}$ & Universo Geek \\
\hline
\end{tabular}

$* \mathrm{EM}=$ Ensino Médio 


\section{Pensando para além dos conceitos de Química: análise dos Materiais Didáticos}

Para análise dos MDs foi utilizada a definição de Freitas (2007, p. 21), que os caracteriza como "todo e qualquer recurso utilizado em um procedimento de ensino, visando à estimulação do aluno e à sua aproximação do conteúdo". A produção dos MDs dos PIs analisados envolveu um processo de pesquisa elaborado pelo licenciando, almejando atender aos objetivos de aprendizagem e a forma como seriam utilizados e desenvolvidos na sequência didática do projeto. Os diferentes tipos de Materiais Didáticos (diretamente relacionados às temáticas dos PIs) foram utilizados da seguinte forma:

$\mathrm{PI}_{1}$ : Os MDs utilizados no projeto foram: Absorventes íntimos femininos e preservativos masculinos, modelos reais e [i] modelos grandes ilustrativos - e duas caixas, uma com [ii] problemas (absorventes íntimos femininos e preservativos masculinos comuns, feitos com polímeros plásticos) e outra caixa com [iii] soluções (preservativos masculinos e absorventes íntimos femininos ecológicos). Os materiais [i] e [ii] foram utilizados inicialmente com a intenção de fazer com que os alunos apresentassem seus conhecimentos prévios a respeito dos diferentes tipos de polímeros plásticos e polímeros plásticos biodegradáveis, para que no decorrer das aulas surgissem soluções [iii] para diminuir os impactos ambientais causados por esses produtos.

$\mathrm{PI}_{2}$ : Neste projeto, o MD é um Livro de Receitas, que foi elaborado junto com os alunos, no decorrer das aulas; para isso, cada aluno sugeriu uma receita que foi relacionada com conceitos químicos abordados no desenvolvimento do projeto. A construção do MD se deu com o objetivo de registrar as relações feitas pelos alunos entre as receitas e determinados conhecimentos de Química

$\mathrm{PI}_{3}$ : $\mathrm{O} \mathrm{MD}$ utilizado neste projeto foram Composteiras Pedagógicas, elaboradas pelos alunos, em uma das aulas durante o desenvolvimento do projeto, com a intenção de proporcionar uma vivência prática a respeito da temática abordada.

$\mathrm{PI}_{4}$ : Os MDs deste projeto, recortes de episódios de seriados que se referem à utilização de diferentes tipos de drogas, foram utilizados com a intenção de compreender o que os alunos sabem sobre os diferentes tipos de drogas e levantar um questionamento a respeito da utilização de algumas drogas como medicamentos e outras não.

$\mathrm{PI}_{5}$ : Este projeto possui dois MDs: [i] diferentes tipos de polímeros plásticos utilizados na construção civil, com a intenção de contextualizar e mostrar para os alunos que existem diversos materiais poliméricos utilizados na construção civil, e; [ii] fotos tiradas pelos alunos, no Epítome, de polímeros encontrados na escola, que foram utilizadas posteriormente na Polinização, com a intenção de fazer com que os alunos explicassem o porquê de terem escolhido tal material para a foto, objetivando compreender os conhecimentos prévios dos mesmos.

$\mathrm{PI}_{6}$ : Os MDs deste projeto foram diferentes produtos cárneos (charque e jerked beef) e carne suína. A carne suína foi utilizada, no decorrer das aulas, para preparar hambúrgueres com a intenção de que os alunos reconhecessem os efeitos causados pela utilização de sais de cura. Além disso, foram entregues os produtos cárneos durante uma roda de conversa, com o intuito de analisar os conhecimentos prévios dos alunos a respeito da utilização de conservantes.

$\mathrm{PI}_{7}$ : Este projeto contém dois MDs, [i] Extratos, Frutas e folhas, utilizados com a intenção de despertar o interesse dos alunos para o tema do projeto, e também para instigá-los a apresentar seus conhecimentos a respeito do assunto. Além desse, [ii] Jogos Didáticos, que foram elaborados pelos alunos (em grupos), sendo esta uma das 
atividades desenvolvidas no decorrer das aulas, com a intenção de estimular os alunos a pesquisarem a respeito de conceitos químicos abordados em aulas anteriores e os relacionarem ao dia a dia, para melhor compreensão e elaboração de jogos contextualizados. Os Jogos Didáticos elaborados foram apresentados na Polinização.

PI8: Os MDs deste projeto são: [i] Histórias em Quadrinhos; [ii] Mangás; [iii] animes, (utilizados para saber quais os alunos conheciam e para que eles compreendessem melhor o tema abordado do projeto); [iv] recorte de desenhos e animações; [v] recortes de episódios de seriados; [vi] compilado de cenas de filmes, e; [vii] Ilustrações (para contextualizar as aulas).

A utilização de MDs alternativos (diretamente relacionados com a temática dos PIs)-teve por objetivo tornar o processo de ensino e aprendizagem mais simples e agradável; assim, a maioria dos MDs foram utilizados na primeira aula, o Epítome, com a intenção de deixar os alunos curiosos a respeito da temática abordada nos PIs. O MD foi utilizado como uma forma de conhecer, considerar e problematizar os conhecimentos prévios dos alunos, com a intenção de iniciar uma discussão a respeito dos diferentes assuntos abordados nos PIs. Esses materiais foram além das atividades comuns no ensino de Química, como listas de exercícios, roteiros e atividades experimentais, que visavam despertar o interesse da turma para a aula.

Salienta-se a importância de valorizar o conhecimento prévio dos alunos, para que eles possam "construir estruturas mentais utilizando, como meio, mapas conceituais que permitem descobrir e redescobrir outros conhecimentos, caracterizando, assim, uma aprendizagem prazerosa e eficaz" (Pelizzari, Kriegl, Baron, Fink e Dorocinski, 20012002, p.37), pois desta forma a aprendizagem pode se tornar mais significativa, ao passo que o aluno se apropria de um novo conteúdo fazendo relação deste com um conhecimento prévio (Pelizzari e outros, 2001-2002).

Ao analisar os MDs a partir dos registros nos projetos, foi possível observar a utilização desses também para outras finalidades, como, por exemplo, para a contextualização e melhor compreensão do tema abordado. Os MDs analisados, de forma geral, contribuíram para deixar as aulas mais lúdicas, dinâmicas e próximas da realidade dos alunos. Percebeu-se que, independentemente das características específicas dos MDs e de sua forma de construção, o que definiu sua relevância nas aulas foi a maneira como estava planejada sua utilização na sequência didática dos PI.

Com a análise dos projetos, verificou-se que os MDs por si só não garantem que as aulas não sejam conteudistas, fragmentadas ou sem sentido para os alunos. Por esse motivo, além do entendimento de como esses materiais se constituíam, foi importante perceber como estava prevista sua utilização nas aulas. Verificou-se que todos os MDs propostos buscaram se relacionar com a temática dos projetos e, em alguns casos, estiveram presentes em vários momentos da sequência didática, como a Composteira Pedagógica, construída com a turma e utilizada no decorrer do desenvolvimento do $\mathrm{PI}_{3}$, sendo utilizada também como base para a apresentação dos alunos no evento de Polinização.

Para construir os MDs e os projetos de forma geral, os licenciandos atuaram como pesquisadores, investigando uma temática que tinha relação com o campo de estágio e relacionando-a com os conteúdos e conceitos de química previstos para serem trabalhados pelo professor da escola. Quando a elaboração do MD ocorreu em conjunto, pelo licenciando com os alunos das escolas de estágio, estes construíram conhecimentos e estratégias de ensino, possibilitando que o processo de ensino e aprendizagem ocorresse de uma forma diferente e significativa, como aconteceu, por exemplo, no $\mathrm{PI}_{2}$, 
$\mathrm{PI}_{3}$ e $\mathrm{PI}_{7}$. Dessa forma, a formação do professor como pesquisador pode possibilitar que, em suas práticas profissionais, eles exerçam a docência de forma a estimular a formação de novos conhecimentos e/ou questionar os conhecimentos prévios dos alunos (Pesce, André, 2012), através da elaboração MDs, por exemplo.

Porém, salienta-se que a construção, envolvendo o planejamento e a elaboração dos PCEs no geral, assim como dos MDs, exige um tempo considerável de planejamento e desenvolvimento, tanto para a respectiva elaboração com/para os alunos, quanto para buscar teorias, metodologias e estratégias didáticas para sua organização.

\section{Pensando para além dos conceitos de Química: análise dos Epítomes e Polinizações}

Nesta seção, serão apresentados, de forma breve, o Epítome e a Polinização de cada um dos oito PIs, assim como a análise dos mesmos.

Começamos pela apresentação dos Epítomes, que tinham a intenção de aproximar os alunos das temáticas propostas, caracterizando o início da relação entre teoria e prática, entre ciência e realidade, sendo um momento fundamental para a realização do projeto (Zwierewicz, 2014).

$\mathrm{PI}_{1}$ : No Epítome desse projeto, os alunos foram questionados a respeito do que sabiam a respeito de produtos de higiene, e de que materiais são feitos os absorventes femininos e os preservativos masculinos. A partir do conhecimento prévio dos alunos, iniciava-se, então, uma explicação a respeito de polímeros, seus impactos ambientais e possíveis substitutos menos prejudiciais ao meio ambiente.

$\mathrm{PI}_{2}$ : Neste projeto, foi utilizada a metodologia "Brainstorming" no Epítome, envolvendo conceitos do ensino através do conhecimento e opinião prévia do aluno. Para isso, os alunos formaram um ciclo de debates para conversarem a respeito do que eles achavam que é a Química, com a intenção de iniciar um debate através dos conceitos apontados pelos alunos, problematizando, desconstruindo e construindo ideias a respeito do assunto.

$\mathrm{PI}_{3}$ : O Epítome deste projeto foi realizado em um piquenique, no jardim da escola, objetivando uma maior interação entre os alunos e a temática proposta. No piquenique, foi realizada uma roda de conversa, iniciada com uma questão a respeito de onde e o que se pode estudar na Química, cujas respostas dos/das alunos deram origem a uma explicação a respeito da temática do projeto. Após a explicação, os alunos, em grupos, registraram, por meio de palavras e desenhos em um papel pardo, suas impressões, dúvidas e ideias em relação à temática.

$\mathrm{PI}_{4}$ : Neste projeto, para o Epítome, os alunos formaram um círculo, com a intenção de fazer uma roda de conversa, para que fosse possível debater sobre a temática do projeto, drogas lícitas e ilícitas, com o intuito de investigar o conhecimento desses alunos a respeito da temática.

$\mathrm{PI}_{5}$ : No Epítome deste projeto foi proposta uma atividade investigativa, em que os alunos tiraram fotos do que eles entendiam por materiais poliméricos utilizados na construção civil, na estrutura física da escola, com a intenção de despertar o interesse dos alunos pela temática proposta. Após realizar a atividade, as fotos foram projetadas, para que os alunos justificassem o motivo de terem fotografado aqueles materiais, o porquê de considerá-los um polímero, gerando assim um debate através dos conhecimentos que os alunos tinham a respeito do assunto. 
PI6: Neste projeto, para o Epítome, os alunos formaram um círculo, e então foram apresentados os MDs, produtos cárneos, para que fossem lidos os rótulos, depois, considerando o conhecimento prévio dos alunos, foi problematizada a utilização de conservantes desses produtos, temática abordada no PI.

$\mathrm{PI}_{7}$ : No epítome deste projeto, os alunos também foram convidados a formar um círculo, e então a temática do projeto foi apresentada; a seguir, foram entregues os MDs [i], com a intenção de deixar o momento mais descontraído, contextualizar a temática e investigar o que os alunos entendiam por "Aromas", e a partir dos conhecimentos deles, foi iniciada a explicação a respeito dos aromas dos alimentos.

$\mathrm{PI}_{8}$ : Para realizar o Epítome deste projeto, foi solicitado que os alunos formassem um semicírculo, e então foi apresentada a temática do projeto; na sequência, com a intenção de investigar quais os animes/mangás/HQs os alunos conheciam e de quais gostavam mais, foi realizada uma roda de conversa. Para os alunos que não conheciam a temática, foram apresentadas imagens, possibilitando assim que contribuíssem durante a conversa.

Em todos os Epítomes, além da apresentação da temática, dos conceitos e conteúdos que seriam discutidos nas regências, foram apresentadas as atividades que seriam desenvolvidas no projeto, inclusive a Polinização, assim como as formas de avaliação e o cronograma das aulas.

A respeito da Polinização, Zwierewicz (2014, p. 76) afirma que "consiste na socialização e difusão dos resultados do projeto no entorno em que foi desenvolvido e em outros contextos, dando vida à proposta matricial, de tal modo que as ideias e valores sigam ativos em outras comunidades, escolas, pessoas". Desse modo, a Polinização, tendo como objetivo concluir o desenvolvimento do projeto, através da socialização e apresentação dos resultados alcançados e dos MDs desenvolvidos, foi realizadas da seguinte forma:

$\mathrm{PI}_{1}, \mathrm{PI}_{4}$ e PI 7 : As polinizações dos PIs 1,4 e 7 foram desenvolvidas em conjunto, através de apresentações das turmas e grupos de alunos, no estilo "feira de ciências", na quadra de esportes da escola, dos trabalhos desenvolvidos no decorrer das aulas. A turma onde foi aplicado o $\mathrm{PI}_{1}$ fez apresentação sobre os polímeros presentes nos absorventes íntimos femininos e os preservativos masculinos, seus impactos ambientais e alternativas ecológicas. A turma do $\mathrm{PI}_{4}$ realizou apresentações sobre pesquisas realizadas a respeito de drogas e medicamentos. E, por fim, a turma onde foi aplicado o $\mathrm{PI}_{7}$, apresentou os MDs [ii], os Jogos Didáticos desenvolvidos, a respeito dos assuntos vistos em aula. Para assistir as apresentações, foram convidados todos os professores da escola. A Polinização contou também com a participação do jornalista do IFSC, que fez a cobertura do evento e o divulgou na página do IFSC.

$\mathrm{PI}_{2}$ : Na polinização deste projeto, foram sugeridas, pelos alunos, receitas que fizeram parte do Livro de Receitas, o material didático do PI. Então, os alunos apresentaram, em forma de seminários, a receita escolhida para o livro, fazendo associação aos conceitos abordados durante as aulas.

$\mathrm{PI}_{3}$ : Neste projeto, para a Polinização, foi realizado um evento, com a participação dos professores de Ciências e de Física, e de alunos de outras turmas, da escola onde o projeto foi desenvolvido. No evento, que aconteceu no auditório, foi apresentado um vídeo de atividades realizadas com os alunos no decorrer das aulas, foram apresentados seminários pelos alunos a respeito da temática abordada no projeto, 
e também foi apresentada a composteira que ficaria na escola, elaborada a partir dos MDs desenvolvidos durante as aulas.

$\mathrm{PI}_{5}$ : Para esta Polinização, foi realizado um compilado das pesquisas realizadas pelos alunos, através de uma atividade, a respeito dos materiais fotografados no Epítome. Além disso, foi elaborado um material que foi publicado no site da escola, divulgando assim os trabalhos realizados pelos alunos. Por fim, os alunos apresentaram um seminário, com a intenção de socializar as informações das pesquisas com os colegas.

PI6: A Polinização deste projeto ocorreu através de seminários, realizados por grupos de alunos, com o objetivo de compartilhar com os alunos de outras fases e professores de outras disciplinas do curso os conhecimentos teóricos e práticos a respeito das análises de conservantes em produtos cárneos.

$\mathrm{PI}_{8}$ : Neste projeto, a Polinização foi realizada através da apresentação (seminários) das Histórias em Quadrinhos, elaboradas em grupos, utilizando os conceitos químicos abordados no decorrer das aulas.

Através das Polinizações, que foram realizadas de maneiras bem distintas, envolvendo diferentes sujeitos das práticas educativas, os projetos foram finalizados com apresentações, realizadas pelos alunos, das diferentes pesquisas e/ou MDs elaborados no decorrer das aulas. Os resultados foram também socializados pelos licenciandos no seminário de estágio que ocorre semestralmente no IFSC-SJ.

De acordo com Santos e Schnetzler (2010, p.56), a educação científica deve "contribuir para preparar o cidadão a tomar decisões, com consciência do seu papel na sociedade, como indivíduo capaz de provocar mudanças sociais na busca de melhor qualidade de vida para todos". Levando isso em conta, com a elaboração de PIs baseados em PCEs, foi possível adotar diferentes estratégias metodológicas, com a intenção de oferecer aulas que possam formar sujeitos capazes de participar de decisões tomadas para e na sociedade. Nesse sentido, a utilização de diferentes estratégias metodológicas nos estágios pode auxiliar o futuro professor, na capacidade de "analisar, criticar, refletir de uma forma sistemática sobre sua prática docente, com o objetivo de conseguir uma transformação escolar e social e uma melhora na qualidade do ensinar e de inovar" (Imbernòn, 1994, apud Pesce e André, 2012, p.40).

As estratégias metodológicas utilizadas nos PIs analisados apresentaram grande relevância, pois, além de auxiliarem na formação do futuro professor e na formação do aluno como cidadão, contribuíram com possibilidades para reflexões sobre Ensino de Química, que tem como principais características o conteudismo, a fragmentação, a linearidade e a excessiva memorização de conceitos. Muitas vezes, são características como essas que fazem com que muitos alunos vejam os conhecimentos relacionados aos conteúdos de Ciências da Natureza e suas Tecnologias como difíceis, bem como apresentem dificuldades em aprender, relacionar e utilizar esses conhecimentos em situações práticas do dia a dia (Maldaner e Zanon, 2001).

Nos PIs analisados, além das estratégias metodológicas, as diferentes abordagens temáticas foram utilizadas como forma de sair da perspectiva tradicional de ensino, buscando superar esse ensino linear, fragmentado e descontextualizado que tende a estar presente no Ensino de Química, conforme afirmado por Maldaner e Zanon, (2001), e transformar a realidade dos alunos, fazendo com que observem que os conteúdos de estudo da química estão presentes em nosso cotidiano. 
Além de os PIs apresentarem uma proposta de Ensino de Química diferenciada a partir de abordagem temática, foi possível perceber neles a valorização dos conhecimentos prévios dos alunos por parte dos licenciandos. Percebeu-se que é possível elaborar um projeto que parta da realidade do aluno, com a intenção de cativálos, de fazer com que queiram aprender (Paro, 2002), de tornar o processo de ensino e aprendizagem algo interessante para eles, que tenha sentido e significado em suas vidas.

A realização dos diferentes tipos de pesquisas feitas nos ES (leitura dos referenciais teóricos, observações participantes e aplicação de atividades investigativas) foi importante para elaborar PIs que fossem realmente significativos para os alunos, pois, para isso, foi preciso conhecer os mesmos e também o espaço escolar, buscar entender suas realidades, anseios e potencialidades.

\section{Considerações finais}

A análise apresentada neste texto evidenciou a relevância dos PIs na formação de professores de química, pois, concordando com Pesce e André (2012, p. 49), "a formação do professor pesquisador significa proporcionar a construção de uma forma de pensar curiosa, observadora, reflexiva e analítica". Dessa forma, a organização dos estágios a partir da pesquisa auxiliou os futuros professores em seu desenvolvimento profissional, possibilitando que sejam capazes de analisar dados necessários para o trabalho docente, buscando a formação de sujeitos críticos e reflexivos, que aprendam os conteúdos químicos e suas relações com as práticas culturais em que estão inseridos.

Os processos de pesquisa realizados durante a construção dos PIs nos estágios supervisionados foram importantes para desenvolver projetos baseados na opinião e nas preferências dos alunos, para a definição da temática, a escolha das atividades e avaliações aplicadas no decorrer do bimestre, nas metodologias utilizadas, fazendo com que cada projeto apresentasse particularidades da turma em foi aplicado. Verificou-se que a elaboração de PIs, baseados em PCEs, no estágio supervisionado, pode contribuir para a formação de professores que não se limitam a trabalhar dentro de uma perspectiva conteudista, focada na transmissão e memorização de conteúdos e conceitos de Química, e sim professores pesquisadores que articulam conceitos e conteúdos químicos com a intenção de apresentar um tema maior, que tenha um significado e esteja presente no dia a dia dos alunos, estimulando a construção da autonomia intelectual e do pensamento crítico, conforme previsto no projeto pedagógico do curso (IFSC, 2014).

Ao final do semestre, os projetos desenvolvidos são divulgados no Seminário de Estágios, que ocorre semestralmente no IFSC-SJ, como uma forma de socializar as experiências relacionadas ao Ensino de Química, utilizando-se de diferentes formas de ensino, socialização, reflexões e pesquisas realizadas para o desenvolvimento dos ES, que podem contribuir para processos de ensino e aprendizagem realizados em outros espaços educativos.

No geral, os componentes curriculares, no decorrer do curso de Licenciatura em Química do IFSC-SJ, apresentam um processo de construção, em que é realizada uma formação inicial, voltada para a formação de professores pesquisadores. Esse processo continua no desenvolvimento dos estágios, pois, concordando com Leite (2011, p. 47), é nos estágios que o licenciando busca compreender "o exercício da docência, a valorização e o desenvolvimento dos saberes dos professores como sujeitos intelectuais 
capazes de produzir conhecimento" e, também, é onde a teoria e a prática se tornam elementos indissociáveis. Dessa forma, a participação do licenciando em atividades que articulem o ensino, a pesquisa e a extensão, como os estágios no curso analisado, auxilia a formação do futuro professor, oportunizando vivências em situações do cotidiano escolar, demonstrando a indissociabilidade entre a teoria e a prática.

Sendo assim, podemos considerar que os componentes curriculares de ES do curso de Licenciatura em Química do IFSC-SJ apresentam uma perspectiva de formação de professores pesquisadores que se caracteriza "como experiência transformadora e formadora, como tempo de aprofundar na relação entre educação, ciência e tecnologia" (Arroyo, 2019, p. 27).

\section{Referências}

Arroyo, M. G. (2019). Estágios - Um convite a radicalizar sua função formadora. Aguiar, P. A., Drews, F., Demos, T. V., Pereira, G. A. e Vaz, K. (Orgs.), Estágios Supervisionados na Formação Docente: Experiências e Práticas do IFSC-SJ. (pp.14-30). Florianópolis: IFSC.

Aguiar, P. A., Pereira, G. A. e Viella, M. A. L. (2017). O uso da metodologia dos Projetos Criativos Ecoformadores (PCE) no estágio curricular supervisionado de um curso de licenciatura do Instituto Federal de Santa Catarina (IFSC) Campus São José. Revista Professare, 6(2), 123-140.

Freitas, O. (2007). Os equipamentos e materiais didáticos. Brasília: Universidade de Brasília. Centro de Educação a Distância. Brasília: Universidade de Brasília, Recuperado em 20 de maio de 2019, de http://portal.mec.gov.br/seb/arquivos/pdf/profunc/equipamentos.pdf.

Garcez, E. S. C., Gonçalves, F. C., Alves, L. K. T., Araújo, P. H. A., Soares, M. H. F. B. e Mesquita, N. A. S. (2012). O Estágio Supervisionado em Química: possibilidades de vivência e responsabilidade com o exercício da docência. Alexandria Revista de Educação em Ciência e Tecnologia, 5(3), 149-163.

Instituto Federal de Santa Catarina - IFSC. (2014). Projeto Pedagógico do curso de Química - Licenciatura. São José: IFSC Campus São José.

Leite, Y. U. F. (2011). Sobre os estágios no curso de formação de professores. Y. U. F. Leite (Org.). O lugar das práticas pedagógicas na formação inicial de professores (pp.45-56). São Paulo: Cultura Acadêmica.

Lüdke, M. (2012). A complexa relação entre o professor e a pesquisa. André, M. (Org.). O papel da pesquisa na formação e na prática dos professores (pp. 27-24). 12a ed. São Paulo: Papirus.

Maldaner, O. A. e Zanon, L.B. (2004). Situação de estudo: uma organização do ensino que extrapola a formação disciplinar em ciências. Moraes, R.; Mancuso, R. (Orgs.). Educação em ciências: produção de currículo e formação de professores (pp. 43-64). Ijuí, Rio Grande do Sul: Editora Unijuí.

Neves, J. L. (1996). Pesquisa Qualitativa - características, usos e possibilidades. Caderno de pesquisas em administração, 1(3), 1-5. 
Nunes, C. M. F. (2001). Saberes docentes e formação de professores: um breve panorama da pesquisa brasileira. Educação \& Sociedade, 22(74), 27-42.

Paro, V. H. (2002). Implicações do caráter político da educação para a administração da escola pública. Educação e pesquisa, 28(2), 11-23.

Pelizzari, A., Kriegl M. L., Baron, M. P., Fink, N. T. L. e Dorocinski, S. I. (2001-2002). Teoria da aprendizagem significativa segundo Ausubel. Revista PEC, 2 (1), 3742. Recuperado em 20 de março de 2019, de http://portaldoprofessor.mec.gov.br/storage/materiais/0000012381.pdf

Pesce, M. K. e André, M. E. D. A. (2012). Formação do professor pesquisador na perspectiva do professor formador. Revista Brasileira de Pesquisa sobre Formação Docente, 4(7), 39-50.

Pimenta, S. G. (1999). Formação de professores: identidade e saberes da docência. PIMENTA, S.G. (Org). Saberes pedagógicos e atividade docente. (pp.15-34). São Paulo, São Paulo: Cortez Editora.

Pimenta, S. G. e LIMA, M. S. L. (2005/2006). Estágio e Docência: diferentes concepções. Revista Poiésis, 3(3 e 4), 5-24.

Santos, W. L. P. e Schnetzler, R. P. (2010). Ensino de Química e a formação do cidadão. W. L. P. Santos e R. P. Schnetzler (Orgs.). Educação em Química: compromisso com a cidadania. $4^{\mathrm{a}}$ ed. (pp.43-58). Ijuí: Unijuí.

Silva, R. M. G. e Schnetzler, R. P. (2008). Concepções e ações de formadores de professores de Química sobre o estágio supervisionado: propostas brasileiras e portuguesas. Química Nova, 31(8), 2174-2183.

Torre, S. e Zwierewicz, M. (2009). Projetos criativos ecoformadores. M. Zwierewicz e S. Torre (Coord.). Uma escola para o século XXI: escolas criativas e resiliência na educação. (pp.153-175). Florianópolis: Insular.

Tura, M. L. R. (2003) A observação do cotidiano escolar. N. Zago, M. P. Carvalho, e R. A. T. Vilela (Orgs.) Itinerários de pesquisa. Perspectivas qualitativas na Sociologia da Educação (pp. 183-205). Rio de Janeiro: DP\&A.

Zabalza, M. A. (2004). Diários de Aula: um instrumento de pesquisa e desenvolvimento profissional. Tradução Ernani Rosa. Porto Alegrel: Artmed.

Zwierewicz, M. (2014), Seminário de pesquisa e intervenção I. Florianópolis: Publicações do IFSC.

Zwierewicz, M., Somariva, J. F. G., Bianco, M., Debiasi, M., Cachoeira, R. D., Silva, M. C., Silveira, L., Bratti, M. M. V., Schlickmann, M. M., Zanelato, D. S. L., Marioti, B. e Silva, R. Q. (2016). Escolas Criativas: experiências transformadoras potencializadas na interação do Ensino Superior com a Educação Básica. Polyphonía, 27(1), 393-413.

Data da recepção: 17/09/2019

Data da revisão: $21 / 10 / 2019$

Data do aceite: 23/10/2019 